\title{
Elevated Serum Levels of Estradiol Induce Endometrial Hyperplasia Rather than Carcinoma in a Mouse Model Using a Carcinogen
}

Ryoichi Asaka, Tsutomu Miyamoto*, Yasushi Yamada, Hirofumi Ando, David Hamisi Mvunta, Hisanori Kobara, Hiroyasu Kashima and Tanri Shiozawa Department of Obstetrics and Gynecology, Shinshu University School of Medicine, Japan

*Corresponding author: Tsutomu Miyamoto, Department of Obstetrics and Gynecology, Shinshu University School of Medicine, 3-1-1 Asahi, Matsumoto 390-8621, Japan, Tel: 81-263-37-2719; Fax: 81-263-39-3160; E-mail: tmiya@shinshu-u.ac.jp

Received date: November 21, 2017; Accepted date: November 24, 2017; Published date: December 01, 2017

Copyright: @2017 Asaka R, et al. This is an open-access article distributed under the terms of the Creative Commons Attribution License, which permits unrestricted use, distribution, and reproduction in any medium, provided the original author and source are credited.

\begin{abstract}
Objective: Although estrogen has been regarded as a risk factor for endometrial carcinoma, its concentrationdependent carcinogenetic effects remain unclear, because most endometrial carcinomas occur in post-menopausal women, whose serum estrogen levels are relatively low. We previously reported that high levels of estradiol (E2) may suppress endometrial carcinogenesis by up-regulating DNA mismatch repair (MMR) in vitro. The present study was undertaken to further examine the carcinogenetic role of estrogen at various concentrations in vivo.
\end{abstract}

Methods: N-methyl-N-nitrosourea (MNU) was injected into the uterine cavity of 29 mice, and E2 was administered by pellets or orally. Uteri were removed for histological examinations 24 weeks later, and serum E2 levels were measured. The immunohistochemical expression of MMR proteins in uterine epithelia was investigated.

Results: Of 29 mice, 8, 8, 8, and 5 showed atrophic, normal, hyperplastic, and carcinomatous endometria, respectively. The mean E2 levels of each group were $0.2 \mathrm{pg} / \mathrm{ml}, 3.8 \mathrm{pg} / \mathrm{ml}, 190.0 \mathrm{pg} / \mathrm{ml}$, and $6.7 \mathrm{pg} / \mathrm{ml}, \mathrm{with}$ significant differences. The expression of the MMR proteins was stronger in mice with elevated E2.

Conclusion: Elevated E2 levels preferentially induced endometrial hyperplasia rather than carcinoma, and this may be mediated by MMR proteins. These results indicate that modest E2 is needed, whereas elevated E2 levels are not necessarily advantageous for carcinogenesis, suggesting the importance of low-chronic (un-opposed) estrogen in human endometrial carcinogenesis.

Keywords: Endometrial carcinoma; Endometrial hyperplasia; Estrogen; N-Methyl-N-Nitrosourea; Mismatch repair; Carcinogenesis; Cd-1 Mouse; Low chronic estrogen level

\section{Introduction}

Malignant transformation is more likely to occur in actively dividing cells, because DNA replication errors increase with DNA duplication and mitosis [1]. Normal endometrial glandular cells express estrogen receptors (ER) and their proliferation is stimulated by estrogen [2]. Thus, physiologically elevated serum estrogen levels, approximately $100-300 \mathrm{pg} / \mathrm{ml}\left(10^{-9} \mathrm{M}-10^{-8} \mathrm{M}\right)$ of estradiol (E2) as observed in women with normal menstrual cycles, are presumed to accelerate endometrial carcinogenesis. However, most endometrial carcinomas occur in peri- or post-menopausal women, whose serum estrogen levels are relatively low (less than $100 \mathrm{pg} / \mathrm{ml}$ or $10^{-10} \mathrm{M}$ ) [3]. Serum estrogen levels are also low in women receiving estrogen replacement therapy, a well-known risk factor for the development of endometrial carcinoma [3]. Thus, the actual role of the estrogen load in endometrial carcinogenesis currently remains unclear.

Recent research revealed that genetic abnormalities such as PTEN, PIC3CA, and K-RAS mutations are involved in the early tumorigenesis of endometrial endometrioid-type adenocarcinoma [4], and these events have been more frequently detected in tumors with microsatellite instability (MSI), caused by impaired mismatch repair (MMR) via silencing methylation and mutations in MMR genes $[5,6]$.
These findings indicate that an MMR deficiency is an important event in the early stages of endometrial carcinogenesis. More recently, TCGA data on endometrial carcinoma revealed that approximately $40 \%$ of cases had MSI [7], supporting the importance of MMR in this malignancy. Several studies reported a relationship between estrogen and MMR; the use of estrogen has been shown to reduce the risk of MSI-positive colon cancer [8], and MSI correlated with the absence of ER expression in breast carcinoma [9].

We previously demonstrated that the expression of MMR proteins such as hMLH1 and hMSH2 as well as MMR activity was increased by E2 in cultured normal endometrial glandular cells and ER-positive endometrial carcinoma cells, suggesting that elevated E2 levels suppress endometrial carcinogenesis, and also that relatively low E2 levels may benefit the occurrence of this malignancy in vitro [10]. In order to further understand the role of estrogen in endometrial carcinogenesis in vivo, we employed a mouse endometrial carcinoma model in which carcinoma was induced by an intra-uterine injection of a potent carcinogen, $\mathrm{N}$-methyl-N-nitrosourea (MNU) [11], and examined the effects of various concentrations of E2 on mouse endometrial histology. 
Page 2 of 6

\section{Materials and Methods}

\section{Animals and chemicals}

Twenty-nine female ICR mice (6 weeks old) were purchased from Japan Charles River Co. (Kanagawa, Japan). The care and use of experimental animals were in accordance with institutional guidelines. A basal diet (Oriental MF, Oriental Yeast Co., Tokyo, Japan) and filtered distilled water were provided. Water soluble 17-estradiol (E2) and MNU were purchased from Sigma-Aldrich Co. (St. Louis, MO) Polyethylene glycol (PEG) was purchased from Wako (Tokyo, Japan). E2 pellets $(0.72 \mathrm{mg} /$ pellet 90 -day release) were purchased from Innovative Research of America (Sarasota, FL). This study was performed in accordance with the Regulations for Animal Experimentation of Shinshu University. The animal protocol was approved by the Committee for Animal Experiments of Shinshu University (Approval Number 220084). Based on national regulations and guidelines, all experimental procedures were reviewed and approved by the Committee for Animal Experiments Shinshu University.

\section{Experimental protocols for MNU and E2 administration}

Animal experiments in the present study were performed as described previously [11] with some modifications. In brief, MNU was dissolved in distilled water at a concentration of $1 \mathrm{mg} / \mathrm{ml}$ and $6 \%$ of PEG was added to the solution to increase viscosity. Of 29 mice, $100 \mu \mathrm{l}$ of the MNU solution was injected into each side of uteri in 27 mice, and $100 \mu \mathrm{l}$ of normal saline was injected into 2 mice as a control.

Ovariectomy was additionally performed on 12 mice. In 7 mice, E2 pellets were given twice at the operation for the MNU injection and at 12 weeks after the operation. In 22 mice, E2 dissolved in water was added orally. In this group, mice started drinking E2 solution at various concentrations $\left(0.0 .001,0.01,0.1,1,10\right.$, and $\left.20 \times 10^{-6} \mathrm{~g} / \mathrm{ml}\right)$ after the operation. Twenty-four weeks after the administration of MNU, uteri were removed, fixed in formalin, and embedded in paraffin for histological examinations. Sera were also collected and frozen at $-80^{\circ} \mathrm{C}$ for later analyses. The experimental schedule was summarized in Figure 1 .

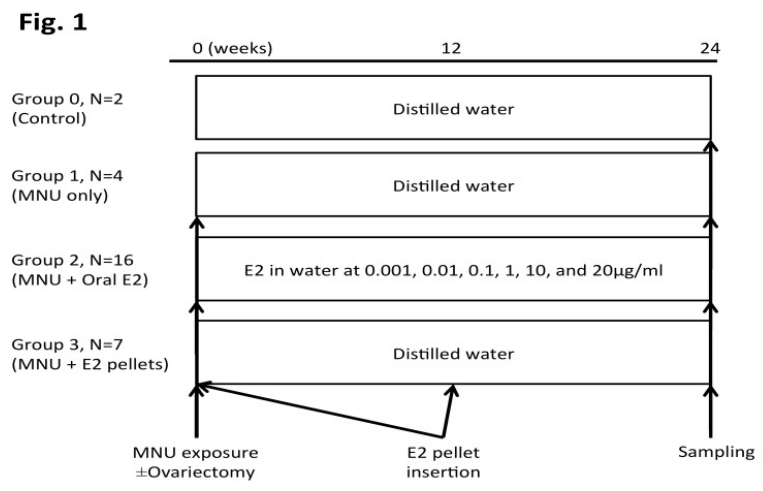

Figure 1: Summary of the experimental schedule. MNU: N-methyl$\mathrm{N}$-nitrosourea; E2: estradiol.

\section{Measurement of serum E2 levels}

Mouse serum E2 levels were measured in 15 mice by an electro chemiluminescence immunoassay (ECLIA) using Cobas e411 (Roche Diagnostics, Basel, Switzerland). Coefficients of variation in this system were less than $4.6 \%$. Since the lower cut-off value of the ECLIA assay is $9.0 \mathrm{pg} / \mathrm{ml}$, remaining 14 mice were analyzed by liquid chromatography-tandem mass spectrometry (LC-MS/MS) using Shimadzu HPLC system (Shimadzu Co. Ltd., Kyoto, Japan) and API5000 (Sciex, Framingham, CA, USA).

LC-MS/MS is highly sensitive, and capable of measuring E2 lower than $9.0 \mathrm{pg} / \mathrm{ml}$. Measurement accuracy was $85 \%$ to $115 \%$ by quality control samples. Inter-assay coefficients of variation were 1.5 to $3.2 \%$, and intra-assay coefficients of variation were 1.5 to $4.9 \%$. In the present study, the serum E2 levels were classified as follows: high E2 level: $>10$ $\mathrm{pg} / \mathrm{ml}$, intermediate E2 level: $1.0 \sim 10 \mathrm{pg} / \mathrm{ml}$, low E2 level: $<1.0 \mathrm{pg} / \mathrm{ml}$. The mean serum E2 level in all estrous stages was reportedly $2.7 \pm 1.0$ $\mathrm{pg} / \mathrm{ml}($ mean \pm SEM) with the highest level being observed in the proestrus stage (approximately $8.0 \pm 3.0 \mathrm{pg} / \mathrm{ml}$ ) [12]. Therefore, moderate E2 levels roughly corresponded to that of the normal E2 range in mice.

\section{Immunohistochemistry and evaluation}

Immunohistochemical staining was performed according to our previous study (10). Rabbit monoclonal anti-MLH1, anti-MSH2, and anti-MSH6 antibodies were used as primary antibodies (dilution1:50; Santa Cruz Biotechnology, Inc., Dallas, TX). After deparaffinization and a microwave treatment, each section was incubated with the primary antibody at $4^{\circ} \mathrm{C}$ overnight.

After washing, sections were visualized using the Histofine MAXPO kit (Nichirei, Tokyo, Japan) and diaminobenzidine. Staining with a rabbit IgG-Isotype control antibody (Abcam, Cambridge, UK) was used as a negative control. Normal human colon tissue was used as a positive control. Immunoreactivity was evaluated according to the intensity of staining by three independent reviewers (R.A., T.M., and Y.Y.), and described as "weak", "moderate", and "strong" because the staining pattern of these MMR proteins was largely homogeneous with limited heterogeneity.

\section{Statistical analysis}

All statistical analyses were conducted using the SPSS Statistics system (IBM, Armonk, NY). The significance of differences was examined using the Mann-Whitney U test, Kruskal-Wallis test, and Fisher's exact test where appropriate. A P value of less than 0.05 was considered significant.

\section{Results}

\section{Serum E2 levels}

Of 29 mice, serum E2 levels were measured using the ECLIA assay in 15 mice. In these 15 mice, 7 showed E2 less than the lower cut-off value $(9.0 \mathrm{pg} / \mathrm{ml})$. Therefore, the E2 level of these 7 mice was tentatively regarded as $4.5 \mathrm{pg} / \mathrm{ml}$ for quantitative analyses. Accordingly, 10 mice showed low serum E2 levels, 11 showed intermediate E2 levels, and 8 showed high E2 levels. The serum E2 level of each mouse with the route of administration and dose of E2 were summarized in Figure 2 . 
Fig. 2

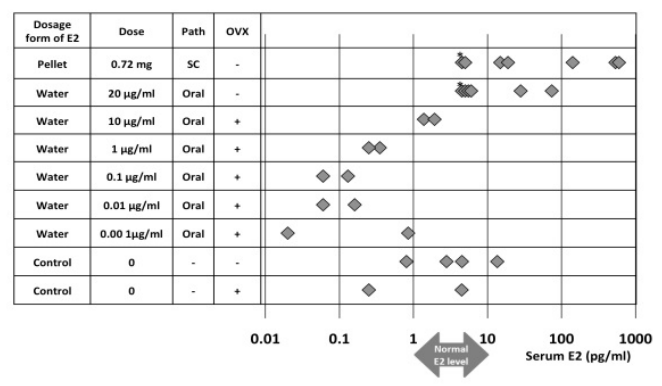

Figure 2: Routes and dose of estradiol (E2) administration, and serum E2 levels of 37 mice. SC: Subcutaneous; OVX: Ovariectomy; *: all dots " $<9.00 \mathrm{pg} / \mathrm{ml}$ " were described as dots for $4.50 \mathrm{pg} / \mathrm{ml}$.

\section{Endometrial histology and serum E2 levels}

The macroscopic figures of extirpated uteri and histological findings of corresponding endometrial tissues were shown in Figure 3. In control mice after ovariectomy, uteri were small and thin (Figures $3 \mathrm{~A}$ and $3 \mathrm{E}$ ) and endometrial epithelia were atrophic. E2-treated mice had larger and heavier uteri than control mice with a normal endometrial morphology (Figures 3B and 3F), and they often had hyperplastic (Figures $3 \mathrm{C}$ and $3 \mathrm{G}$ ) or carcinomatous regions (Figures $3 \mathrm{D}$ and $3 \mathrm{H}$ ).

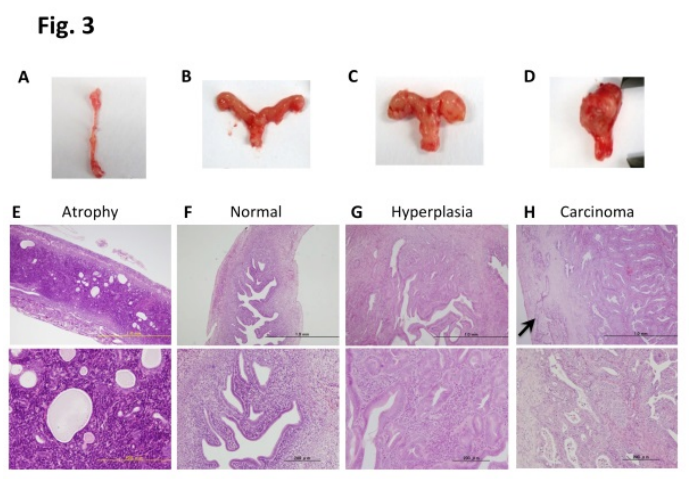

Figure 3: Macroscopic figures of resected uteri (A-D) and corresponding photomicrographs (E-H).A and E: an atrophic uterus and endometrium; $\mathrm{B}$ and $\mathrm{F}$ : a normal uterus and normal endometrium; $\mathrm{C}$ and $\mathrm{G}$ : the uterus is enlarged, and the endometrium is hyperplastic; $\mathrm{D}$ and $\mathrm{H}$ : the uterus is very swollen and shows endometrial carcinoma with deep myometrial invasion (arrow).

Of 29 mice, 8 had atrophic endometria, 8 had normal endometria, 8 had endometrial hyperplasia, and 5 had endometrial carcinoma (Figure 4). Of 8 mice with endometrial hyperplasia, 2 had intermediate E2 levels and the remaining 6 had high E2 levels. Of 5 mice with endometrial carcinoma, one had a high E2 level $(18.9 \mathrm{pg} / \mathrm{ml})$, whereas the remaining 4 had intermediate E2 levels. The mean E2 concentrations ( \pm standard deviation) of mice with atrophic, normal, hyperplastic, and carcinomatous endometria were $0.2 \pm 0.3 \mathrm{pg} / \mathrm{ml}, 3.8$ $\pm 4.6 \mathrm{pg} / \mathrm{ml}, 190.0 \pm 262.1 \mathrm{pg} / \mathrm{ml}$, and $6.7 \pm 8.2 \mathrm{pg} / \mathrm{ml}$, respectively. The mean E2 level was significantly higher in endometrial hyperplasia than in atrophic, normal and carcinomatous endometria $(\mathrm{P}<0.05)$. The incidence of endometrial carcinoma was $19.0 \%$ in the moderate and low E2 groups and $12.5 \%$ in the high E2 group (Table 1). However, this difference was not significant. The incidence of hyperplasia in the high E2 group (75.0 \% vs. 9.5\%) and that of atrophic endometria in the moderate and low E2 groups $(38.0 \%$ vs. $0 \%)$ significantly differed. These results indicated that an intermediate E2 level is suitable for the development of endometrial carcinoma, and high E2 levels induced endometrial hyperplasia rather than carcinoma.

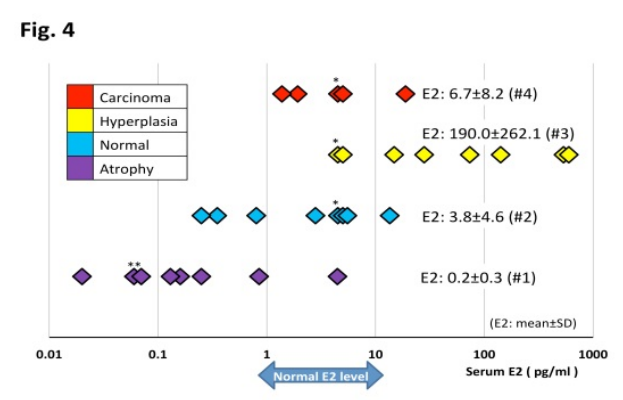

Figure 4: Graphic demonstration of endometrial morphology and the mean serum E2 level of each mouse. \#1:Significantly different $(\mathrm{p}<0.05)$ from Normal, Hyperplasia, and Carcinoma; \#2: Significantly different $(\mathrm{p}<0.05)$ from Atrophy and Hyperplasia; \#3: Significantly different $(\mathrm{p}<0.05)$ from Atrophy, Normal, and Carcinoma; \#4:Significantly different $(\mathrm{p}<0.05)$ from Atrophy and Hyperplasia; ${ }^{*}$ :All dots " $<9.00 \mathrm{pg} / \mathrm{ml}$ " were described as dots for 4.5 $\mathrm{pg} / \mathrm{ml} ;{ }^{* *}:$ There are two dots for $0.06 \mathrm{pg} / \mathrm{ml}$.

\begin{tabular}{|l|l|l|l|l|}
\hline Serum E2 level & Atrophy & Normal & Hyperplasia & Carcinoma \\
\hline Less than $10 \mathrm{pg} / \mathrm{ml}$ & $8(38.0 \%)$ & $7(33.3 \%)$ & $2(9.5 \%)$ & $4(19.0 \%)$ \\
\hline More than $10 \mathrm{pg} / \mathrm{ml}$ & $0(0 \%)^{*}$ & $1(12.5 \%)$ & $6(75.0 \%)^{* *}$ & $1(12.5 \%)$ \\
\hline $\begin{array}{l}* \\
\text { *: Significantly lower incidence from less than } 10 \mathrm{pg} / \mathrm{ml} .(\mathrm{p}<0.05)\end{array}$ \\
* Significantly higher incidence from less than $10 \mathrm{pg} / \mathrm{ml} .(\mathrm{p}<0.05)$
\end{tabular}

Table 1: Serum E2 level and endometrial morphology of each case.

\section{The expression of MMR proteins in mouse endometrial epithelia}

The immunohistochemical expression of MLH1 was mainly observed in the cytoplasm, while that of MHH2 and MSH6 was in the nucleus (Figure 5). In MLH1 staining, mean serum E2 levels in the strong staining intensity group were significantly higher than in the "weak" and "moderate" staining groups $(\mathrm{P}=0.0061$ and $\mathrm{P}=0.0025)$. In MSH2 staining, the mean serum E2 level was higher in the strong staining group but was not significantly different. Although a clear statistical relationship between histological types and E2 levels was not detected, normal or atrophic epithelia often showed weak staining for these proteins, whereas hyperplastic epithelia frequently exhibited strong staining (Figure 5). The moderate expression of MLH1 and 
MSH2 and strong expression of MSH6 were observed in one mouse with endometrial carcinoma containing elevated E2 levels (18.9 pg/ $\mathrm{ml})$.

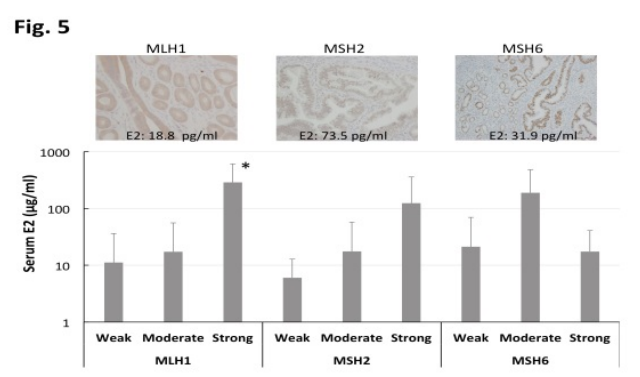

Figure 5: Upper: Representative photomicrographs of the MMR protein immunostaining of endometrial tissues. All three cases were endometrial hyperplasia with elevated E2 levels and strong MMR protein expression. Lower: Graphic demonstration of the immunohistochemical expression of MMR proteins (described as weak, moderate or strong) and serum E2 levels. Mice with strong MLH1 expression showed higher serum E2 levels than those with weak or moderate MLH1 expression with a significant difference ${ }^{*}$ : $\mathrm{p}<0.05)$.

\section{Discussion}

Although endometrial carcinoma is regarded as an estrogendependent tumor, the actual roles of estrogen, particularly its concentration-related effects, on the genesis of this malignancy remain unclear.The present study showed that most MNU-induced endometrial carcinomas were observed in mice with intermediate serum E2 levels, whereas mice with high E2 levels often exhibited endometrial hyperplasia, a precursor of endometrial adenocarcinoma. These results indicate that intermediate E2 levels are preferable for the development of endometrial carcinoma, while elevated or excessive levels of E2 suppressed carcinogenesis, suggesting the "biphasic" role of estrogen on the genesis of endometrial carcinoma.

Several studies reported a role for estrogen in carcinogenesis; however, their conclusions are still somewhat uncertain. In human studies [13-19], serum E2 levels in postmenopausal women with endometrial carcinoma were slightly higher than those in healthy postmenopausal women. However, the baseline E2 levels in both groups were low, i.e., approximately $10 \sim 20 \mathrm{pg} / \mathrm{ml}$, and the difference in $\mathrm{E} 2$ values in both groups were largely less than $5 \mathrm{pg} / \mathrm{ml}$. The biological significance of this small difference appears to be unclear considering that normal E2 may markedly fluctuate from approximately $5 \mathrm{pg} / \mathrm{ml}$ to higher than $300 \mathrm{pg} / \mathrm{ml}$ during a woman's life. In addition, serum E2 levels in premenopausal women with endometrial carcinoma were slightly lower than in healthy controls [13].

The role of E2 is also controversial in mouse models. Several studies demonstrated the carcinogenic effects of estrogen. For example, Niwa et al. showed that the frequency of MNU-induced mouse endometrial carcinoma was increased by the oral intake of E2 [11]. Newbold et al. reported that a subcutaneous injection of E2 and 4-hydroxyestradiol into neonatal mice induced endometrial carcinoma in $7 \%$ and $66 \%$ of injected mice [20]. Vilgelm et al. found that the number of endometrial carcinoma lesions in Pten-/+ mice was reduced by the administration of a pure ERa antagonist, suggesting a positive role of estrogen in tumorigenesis [21]. Jeong et al. reported that the knockout of MIG6, a pivotal downstream molecule in the progestin-induced growth suppression of endometrial carcinoma cells, resulted in the development of endometrial carcinoma following the addition of E2 [22]. In contrast, Joshi et al. showed that Pten-/+ mice developed endometrial carcinoma, whereas the simultaneous knockout of ERa resulted in a higher incidence of endometrial carcinoma, suggesting that endometrial carcinogenesis is independent of estrogen and ERa [23]. Moreover, Saito et al. reported that Pten conditional knockout mice in the endometrium using the Cre-loxP system developed endometrial carcinoma; however, the tumor formation was suppressed by the addition of E2 [24]. This discrepancy may be due in part to methodological differences. In addition, the genetically engineered mice used in these studies may have aberrant MMR systems, which potentially influence the possible relationship between estrogen and MMR. Therefore, the mouse model used in this study has an advantage because it has an intact MMR system. Another important factor is the concentration of E2. Physiological serum levels of E2 in mice reportedly range between from 1 and $10 \mathrm{pg} / \mathrm{ml}$ [12]. However, none of the above-described animal studies examined the concentration of E2 in each mouse used. In the present study, we measured serum E2 levels in each mouse and directly evaluated the effects of serum levels of E2 on tumorigenesis. Consequently, the present study clearly indicated that endometrial carcinoma often occurs in intermediate E2 levels, and elevated E2 suppressed the genesis of endometrial carcinoma, but induced endometrial hyperplasia. This is the first mouse study to demonstrate the concentration-related risk of E2 on endometrial carcinoma.

The present study also showed that the expression of MMR proteins in the endometrial epithelium increased in mice with elevated serum E2 levels. We previously reported that the increased expression of MMR correlated with MMR functions in vitro [10]. Therefore, the elevated immunohistochemical expression of MLH1 and MSH2, which are pivotal for MMR functions, in mice with elevated E2 levels appears to indicate improved MMR function. This result may explain the reduced incidence of cancer in mice with high E2 levels.

Collectively, the concentration-dependent risks of E2 observed in this mouse model are similar to our previous findings using human cultured cells [10]; we revealed that the expression of the MMR protein and its functions were up-regulated by E2 in cultured normal endometrial glandular cells. We then classified endometrial glandular cells into three groups according to E2 levels and proliferative activity. The first group was characterized by high $(>80 \mathrm{pg} / \mathrm{ml})$ serum E2 levels with elevated proliferative activity and strong MMR protein expression, as observed in young women with normal menstruation. The second group was defined by relatively low (20 80 pg/dl) E2 levels with low proliferative activity and low MMR protein expression, as observed in perimenopausal or early postmenopausal women. The third group had low E2 $(<20 \mathrm{pg} / \mathrm{ml})$ levels with no proliferative activity and no MMR protein expression, as observed in late postmenopausal women. The incidence of endometrial cancer is the highest in the second group, i.e., the "intermediate" E2 level group. Potential cancer risks due to active proliferation in the first group were neutralized by strong MMR functions. In the third group, endometria become atrophic and intrinsic cancer risks were low irrespective of the MMR status. Proliferating endometrial epithelial cells without MMR activity were often observed in the second group, and these cells were considered to be cancer "high risk" cells. Based on these findings, we 
proposed a range of intermediate "cancer-prone", E2 levels. The results obtained in the present mouse study support our previous findings.

MNU is a potent chemical carcinogen $[25,26]$ and is widely used to induce mutations and carcinomas [27]. In this mouse endometrial carcinoma model, carcinoma developed within a relatively short time period (20-30 weeks); thus, this model is convenient for the analysis of endometrial carcinogenesis. In previous studies using this model, the frequency of endometrial carcinoma development was approximately $40 \%[11,28,29]$, which was higher than in the present result $(5 / 29,17$ $\%)$. This may be due to differences in the route and dose, and duration of E2 administration, or the effects of progesterone in mice with ovaries. MNU reportedly evokes not only various types of DNA damage [25-27], but also MSI and subsequent point mutations [30-32]. A previous study reported that an intraperitoneal injection of MNU into $\mathrm{CD}$ mice resulted in the development of thymic lymphoma and systemic MSI [30], suggesting that MNU impairs MMR function. In the present study, the elevated expression of MMR proteins was often observed in mice with elevated serum E2 levels. Therefore, the E2induced MMR protein may have counteracted MNU-induced carcinogenesis in mouse endometrial carcinoma, resulting in the formation of endometrial hyperplasia. In the present study, one mouse with elevated E2 levels developed endometrial carcinoma. In this mouse, the expression of MMR proteins was moderate or strong, suggesting that the carcinogenic effects of MNU and E2 overrode the protective effects of MMR proteins. Although the exact mechanisms currently remain unknown, this mouse may represent endometrial carcinoma that occurs in young women with normal estrogen levels and normal menstrual cycle.

\section{Conclusion}

The present study demonstrated that adequate E2 levels are needed for the development of endometrial carcinoma, whereas elevated E2 levels may suppress endometrial carcinogenesis possibly by the upregulation of MMR functions. These results suggest a biphasic role for estrogen in endometrial carcinogenesis and indicate the importance of low-chronic or unopposed estrogen exposure in human endometrial carcinogenesis.

\section{Acknowledgment}

The authors declare that there are no conflicts of interest. This work was supported by JSPS KAKENHI Grant Number 24791696. The authors are grateful to Fumi Tsunoda and Eiji Uchida (Research Assistants;Department of Obstetrics and Gynecology, Shinshu University School of Medicine) for their excellent technical assistance.

\section{References}

1. Hahn WC, Weinberg RA (2002) Rules for making human tumor cells. N Engl J Med 347: 1593-1603.

2. Strauss III J, Coutifaris C (1990) The endometrium and myometrium Reproductive endocrinology. (4thedn), W.B. Saunders Company, Philadelphia, London, Toronto.

3. Hacker NF (2000) Uterine cancer: Practical gynecologic oncology (3rdedn), Lippincott Williams \& Wilkins, Philadelphia.

4. Lax SF (2004) Molecular genetic pathways in various types of endometrial carcinoma: from a phenotypical to a molecular-based classification. Virchows Arch 444: 213-223.

5. Kanaya T, Kyo S, Maida Y, Yatabe N, Tanaka M, et al. (2003) Frequent hypermethylation of MLH1 promoter in normal endometrium of patients with endometrial cancers. Oncogene 22: 2352-2360.
6. Ferreira AM, Westers H, Albergaria A, Seruca R, Hofstra RM (2009) Estrogens, MSI and Lynch syndrome-associated tumors. Biochim Biophys Acta 1796: 194-200.

7. Kandoth C, Schultz N, Cherniack AD, Akbani R, Liu Y, et al. (2013) Integrated genomic characterization of endometrial carcinoma. Cancer Genome Atlas Research Network. Nature 497: 67-73.

8. Slattery ML, Potter JD, Curtin K, Edwards S, Ma KN, et al. (2001) Estrogens reduce and withdrawal of estrogens increase risk of microsatellite instability-positive colon cancer. Cancer Res 61: 126-130.

9. Caldes T, Perez Segura P, Tosar A, de La Hoya M, Diaz Rubio E (2000) Microsatellite instability correlates with negative expression of estrogen and progesterone receptors in sporadic breast cancer. Teratog Carcinog Mutagen 20: 283-291.

10. Miyamoto T, Shiozawa T, Kashima H, Feng YZ, Suzuki A, et al. (2006) Estrogen up-regulates mismatch repair activity in normal and malignant endometrial glandular cells. Endocrinology 147: 4863-4870.

11. Niwa K, Morishita S, Murase T, Mudigdo A, Tanaka T, et al. (1996) Chronological observation of mouse endometrial carcinogenesis induced by N-methyl-N-nitrosourea and 17 beta-estradiol. Cancer Lett 104: 115-119.

12. Nilsson ME, Vandenput L, Tivesten Å, Norlén AK, Lagerquist MK, et al. (2015) Measurement of a Comprehensive Sex Steroid Profile in Rodent Serum by High-Sensitive Gas Chromatography-Tandem Mass Spectrometry. Endocrinology 156: 2492-2502.

13. Potischman N, Hoover RN, Brinton LA, Siiteri P, Dorgan JF, et al. (1996) Case-control study of endogenous steroid hormones and endometrial cancer. J Natl Cancer Inst 88: 1127-1135.

14. Lépine J, Audet Walsh E, Grégoire J, Têtu B, Plante M, et al. (2010) Circulating estrogens in endometrial cancer cases and their relationship with tissular expression of key estrogen biosynthesis and metabolic pathways. J Clin Endocrinol Metab 95: 2689-2698.

15. Lukanova A, Lundin E, Micheli A, Arslan A, Ferrari P, et al. (2004) Circulating levels of sex steroid hormones and risk of endometrial cancer in postmenopausal women. Int J Cancer 108: 425-432.

16. Zeleniuch Jacquotte A, Akhmedkhanov A, Kato I, Koenig KL, et al. (2001) Postmenopausal endogenous oestrogens and risk of endometrial cancer: results of a prospective study. Br J Cancer 84: 975-981.

17. Nyholm HC, Nielsen AL, Lyndrup J, Dreisler A, Hagen C, et al. (1993) Plasma oestrogens in postmenopausal women with endometrial cancer. Br J Obstet Gynaecol 100: 1115-1119.

18. Pettersson B, Bergström R, Johansson ED (1986) Serum estrogens and androgens in women with endometrial carcinoma. Gynecol Oncol 25: 223-233.

19. Allen NE, Key TJ, Dossus L, Rinaldi S, Cust A, et al. (2008) Endogenous sex hormones and endometrial cancer risk in women in the European Prospective Investigation into Cancer and Nutrition (EPIC). Endocr Relat Cancer 15: 485-497.

20. Newbold RR, Liehr JG (2000) Induction of uterine adenocarcinoma in CD-1 mice by catechol estrogens. Cancer Res 60: 235-237.

21. Vilgelm A, Lian Z, Wang H, Beauparlant SL, Klein Szanto A, et al. (2006) Akt-mediated phosphorylation and activation of estrogen receptor alpha is required for endometrial neoplastic transformation in Pten $+/$ - mice. Cancer Res 66: 3375-3380.

22. Jeong JW, Lee HS, Lee KY, White LD, Broaddus RR, et al. (2009) Mig-6 modulates uterine steroid hormone responsiveness and exhibits altered expression in endometrial disease. Proc Natl Acad Sci U S A 106: 8677-8682.

23. Joshi A, Wang H, Jiang G, Douglas W, Chan JS, et al. (2012) Endometrial tumorigenesis in Pten $(+/-)$ mice is independent of coexistence of estrogen and estrogen receptor $\alpha$. Am J Pathol 180: 2536-2547.

24. Saito F, Tashiro H, To Y, Ohtake H, Ohba T, et al. (2001) Mutual contribution of Pten and estrogen to endometrial carcinogenesis in a PtenloxP/loxP mouse model. Int J Gynecol Cancer 21: 1343-1349.

25. Sukumar S, Armstrong B, Bruyntjes JP, Leav I, Bosland MC (1991) Frequent activation of the Ki-ras oncogene at codon 12 in N-methyl-N- 
Citation: Asaka R, Miyamoto T, Yamada Y, Ando H, Hamisi Mvunta D, et al. (2017) Elevated Serum Levels of Estradiol Induce Endometrial Hyperplasia Rather than Carcinoma in a Mouse Model Using a Carcinogen. J Carcinog Mutagen 8: 308.doi: 10.4172/2157-2518.1000308

Page 6 of 6

nitrosourea-induced rat prostate adenocarcinomas and neurogenic sarcomas. Mol Carcinog 4: 362-368.

26. Bosland MC, Prinsen MK, Rivenson A, Weisburger JH (1992) Induction of skin and thyroid tumors in male rats by $\mathrm{N}$-methyl-N-nitrosourea after sequential treatment with cyproterone acetate and testosterone propionate: effects of castration, rat strain and time of carcinogen injection Carcinogenesis 3: 669-674.

27. Mallikarjuna GU, Dhanalakshmi S, Raisuddin S, Rao AR (2003) Chemomodulatory influence of Ferula asafoetida on mammary epithelial differentiation, hepatic drug metabolizing enzymes, antioxidant profiles and $\mathrm{N}$-methyl-N-nitrosourea-induced mammary carcinogenesis in rats. Breast Cancer Res Treat 81: 1-10.

28. Niwa K, Hashimoto M, Morishita S, Yokoyama Y, Lian Z, et al. (2000) Preventive effects of danazol on endometrial carcinogenesis in mice Cancer Lett 158: 133-139.
29. Onogi K, Niwa K, Tang L, Yun W, Mori H, et al. (2006) Inhibitory effects of Hochu-ekki-to on endometrial carcinogenesis induced by $\mathrm{N}$-methyl$\mathrm{N}$-nitrosourea and 17beta-estradiol in mice. Oncol Rep 16: 1343-1348.

30. Huo X, Zhang S, Li Z, Gao J, Wang C, et al. (2015) Analysis of the relationship between microsatellite instability and thymic lymphoma induced by $\mathrm{N}$-methyl-N-nitrosourea in C57BL/6J mice Mutat Res 771 : 21-28.

31. Zuo B, Du X, Zhao J, Yang H, Wang C, et al. (2012) Analysis of microsatellite polymorphism in inbred knockout mice. PLoS One 7: e34555.

32. Du X, Cui J, Wang C, Huo X, Lu J, et al. (2013) Detected microsatellite polymorphisms in genetically altered inbred mouse strains. Mol Genet Genomics 288: 309-316. 